\title{
INTEGRATING IS AND HCI USING ACTIVITY THEORY AS A PHILOSOPHICAL AND THEORETICAL BASIS
}

\author{
Helen Hasan, \\ Department of Business Systems, \\ University of Wollongong, Australia \\ helen_hasan@uow.edu.au
}

\begin{abstract}
The fields of Information Systems (IS) and Human-Computer Interaction ( $\mathrm{HCl}$ ) are both multidisciplinary in nature and each is searching for an identity as a legitimate discipline in its own right, with a firm theoretical basis. Activity Theory offers a set of concepts, structures and terms which are eminently suited to both fields. It has its origins in the cultural historical psychology of Russia, and avoids the dichotomies between thought and action, and between individuals and society, that are prevalent in westem thinking.

This paper describes the basic principles of Activity Theory as they apply to IS and HCI, with particular emphasis on those systems which provide knowledge about the progress of their organisation to senior managers. Activity Theory principles will be used in a longitudinal case study to analyse an extensive project which attempted, with limited success, to produce management support systems in an organisation. The Activity Theory analysis indicates that an integrated IS and $\mathrm{HCl}$ approach would have improved the outcomes of this project.
\end{abstract}

\section{INTRODUCTION}

The fields of information systems (IS) and human-computer interaction (HCI) have much in common. Over the past 10 to 20 years there has been an emergence of new conferences, journals and professional associations in both IS and HCI but both fields are still searching for identities as legitimate disciplines in their own right.

Davies and Ledington (1991) assert that information systems is a hybrid field which is attached to many other disciplines. They claim that, as information is central to our lives, attempts to restrict it to a single area of study are futile. At the same time Carroll (1991) describes human-computer interaction as an interdisciplinary area of applied research and design practice. Mantovani (1996) warns however that the necessary multi-disciplinary work, crossing barriers separating scientific cultures, can be "highly effort demanding, time consuming, and sometimes distressing, requiring as it does negotiation among researchers with different ways of speaking and thinking".

\section{Information Systems}

The field of IS grew in an era when large transaction processing systems were created and maintained in organisations by specialised IS staff. The field's formal methods of systems analysis and design (SA\&D) are best suited to the development of operational systems which automate tedious work processes. In the traditional linear SA\&D lifecycle, users were viewed as people from whom to get initial requirements and, later on, were there to test and use the final product.

A popular IS textbook by Alter (1996) states that "an information system is a system that uses information technology to capture, transmit, store, retrieve, manipulate, or display information used in one or more business processes". This is a common usage of the term but contains several statements which can be questioned. Must an IS be computer-based or even rely on technology at all? What is "information"? Are IS only found in a business context? Where is the boundary of an IS; does it just include the information processing technology, or should it include people and work processes in the "system"? The fact that these questions arise is symptomatic of the confusion regarding the philosophical and theoretical foundations of IS.

If IS research has any traditional base it must surely be General Systems Theory (GST). The systems approach would treat the computer technology, its human users and any relevant part of the organisation as one whole integrated purposeful system. Systems theorists insist that the system's approach may be the only valid treatment of some problems and the only way to "create coherence out of chaos" (van Gigch 1978), even though they admit that such systems are inherently complex and hence difficult to manage. However in practice, many researchers and most practitioners restrict their view of IS to little more than the textbook definition of Alter (1996) as stated above.

\section{Human-Computer Interaction}

The advent of the personal computer has brought software products into use by the wider community, and the use of computers has become an object of research by ergonomists, psychologists and others. The result has been the emergence of the field of Human-Computer Interaction (HCI) which focuses on the users, and the usability, of systems. A significant proportion of $\mathrm{HCI}$ research has looked at commercial software packages 
such as word-processors (see for example the seminal work of Card et al 1983) and the introduction of "userfriendly" operating systems (such as the famous Star Interface from Xerox, the forerunner of the Macintosh) (Preece 1994).

$\mathrm{HCI}$ has been strongly influenced by the fields of computer science, cognitive psychology and ergonomics (human factors). According to Carroll (1991) its key concern is to understand and facilitate the creation of "user interfaces", that is, of computers as manipulated by human users. This places the human and the machine on an equal footing as two interacting information processing systems where the output of one is the input of the other (Aboulafia \& Gould 1995). This cognitive science view of $\mathrm{HCI}$ has reached its limitation from the point of view of prominent $\mathrm{HCI}$ researchers such as Norman (1991) and Carroll (1991).

\section{System which "Informate"}

Zuboff (1988) makes a useful distinction between computerised systems which "automate" as opposed to those which "informate". Examples of systems which "informate" are Executive Information Systems (EIS), Decision Support Systems (DSS), Expert Systems (ES) and Intranets. Neither IS or $\mathrm{HCI}$ have a strong record in dealing with these types of systems and so they are used here to highlight current concerns in these fields.

The strength of $\mathrm{HCI}$ is its focus on, and insistence on the involvement of, users in every phase of system development. It favours an evolutionary prototyping approach using participatory design (PD) or joint application design (JAD) techniques (Hasan \& Gould 1996, Hasan et al 1996). However when users are senior managers it is difficult to get them involved in the time consuming PD or JAD process.

The strength of IS is its incorporation of business needs in systems development, but it relies on the establishment of a thorough set of user requirements before the design and implementation phases. With informate-type systems, the standard IS techniques of observation and interview, may only elucidate vague requirements from users when they are busy executives (Hasan \& Lampitsi 1995).

A comprehensive, holistic approach is essential for the study of projects such as the development of systems to informate, where the user information requirements are unclear and cooperation is required across many organisational units. It will be shown in this paper, that there are at least two complex activities interacting with each other in such projects: the activity of system production (the focus of IS) and the activity of system use (the focus of $\mathrm{HCI}$ ). Too often those involved in each one of these activities does not appreciate the importance and the complexity of the other.

Research in this area must contend with dynamic interactions between individuals and groups, within a complex environment and served by sophisticated technology. Activity Theory offers a set of concepts, structures and terms which are eminently suited to this type of research. It has its origins in the cultural historical psychology of Russia as propounded by Vygotsky in the early $20^{\text {th }}$ century. For this reason it avoids the dichotomies between thought and action and between individuals and society that are prevalent in western thinking (Blackler 1993).

This paper will investigate the special characteristics of informate-type systems and describe the basic principles of Activity Theory as they are applicable to systems which provide information or knowledge about the progress of the organisation. Activity Theory principles will be used to draw parallels between IS and $\mathrm{HCl}$, and a study will be presented where these principles have been used.

\section{MSS: INFORMATION SYSTEMS SUPPORT FOR MANAGEMENT}

With the increasing recognition that information is an important organisational resource, has come a demand for systems that bridge the gap between the huge quantities of raw data in company databases and the provision of useful information to support management. Business Intelligence (BI), Executive Support Systems (ESS), Executive Information System and more recently Intranets and knowledge management, are some of the commonly used names for systems which aim to provide information in a form that suits the styles and tasks of senior managers. These, together with DSS and Expert Systems, are now among the most strategic systems in organisations and will be collectively referred to in this paper as Management Support Systems (MSS).

In the late 1980s, the work of Rockart and De Long (1988) on ESS contested the notion that rigid computer systems were essentially alien to the unstructured and flexible work of senior managers and provided case studies where ESS were becoming indispensable to the work of many executives. However many organisations still do not have a functional information system that is relevant to the work of senior executives and there remains the complex problem of determining the requirements of the system which differ from industry to industry, organisation to organisation and from manager to manager.

The work of strategic decision makers has always been inherently complex and "unstructured" (Mintzberg 1975, Mintzberg et al 1976), but more so today than ever, as the political, economic and social climate is constantly changing. To establish initial specifications for a MSS, it would be worthwhile to have an understanding of the 
characteristics of the managers, the roles they adopt and the activities in which they engage, using a list of generic management styles, roles and activities such as those published by Fidler and Rogerson (1996). These general characteristics could then be used to determine the composition of a MSS that would support the identified management styles, roles and activities. The contentious issue here is the degree of processing of the data supplied to the MSS. Do executives require highly summarised data, or something more in the form of information or knowledge? This question raises a debate on the definition of these 2 terms.

\section{Data, Information or Knowledge?}

There has been debate in the IS community on the IS distinction between data, information and knowledge (ISWORLD 1997). The discussants in this debate agreed that data are the raw facts, events and figures, in fact, the carriers of information and knowledge. Most definitions of information implied that information is data which has been sufficiently processed as to be immediately useful and thus is relative to its use. There was even the suggestion that, in common use, information is simply the output of a computer.

Knowledge was defined in a number of ways such as "information which has been internalised and results in enhanced operations" or "the application of a combination of instincts, ideas, rules and procedures that guide actions and decisions" and that knowledge "normally causes some change in your internal mental map of the external world". The point was also made in the discussion that the field of IS should no longer be concerned with data processing or information processing but knowledge management.

These concepts are relevant to the design of computer support for senior executives. Cognitive research shows that people use map-like structure to make sense of information (Fiol 1992) and cognition can be defined as the activity of knowing: the acquisition, organisation and use of knowledge (Neisser 1976). Norman (1991) states that managers have working mental models of their organisation and Fiol (1992) argues that the broad strategic concerns of managers require a portfolio of different kinds of cognitive maps which are used as a decision aid. She contends that the interaction among these maps is important, as is the recognition that many of these maps are in the form of ingrained, and taken-for-granted, assumptions. Wagner (1995) observes that decision makers in organisations continually face "messy", wide-and-open, non-quantitative problems and proposes techniques that rely on the human problem solver to "make sense" of the problem in a structured way.

A related concept, used by Kuutti and Virkkunen (1995), Randall et al (1996) and others, is the term "organisational memory", a metaphor relating to the collective memories of an organisation's members. The need for "organisational memory" may be a consequence of restructuring and downsizing when organisations discover that much of the organisation's "knowledge" leaves with sacked or released employees. Kuutti and Virkkunen (1995) propose that there should be methods and systems which can capture this "knowledge" and make it available to new members of the organisation.

In summary an ideal MSS should provide knowledge management that enhances the accuracy of managers "mental maps", support the solution of "messy" problems and captures organisational memory. It should be relevant to the management styles of real people in the roles they play and the activities in which they engage. MSS designers must anticipate changing requirements and be sensitive to the context in which it will be used.

A framework in which this can be done is that provided by Activity Theory. The reasons for this choice will be elaborated below but are well articulated by Blackler (1993) in his review of the relationship between knowledge organisation and the management, where he says "Activity Theory reframes management by modelling the recurrent and embedded nature of human activities, by revealing the tentative nature of knowledge and its action orientation and by highlighting the opportunities for individual and collective development that engagement and dilemma can provide".

\section{PRINCIPLES OF ACTIVITY THEORY}

Activity Theory has its roots in the work of the Russian psychologist Vygotsky during the first half of this century, and is based on the idea that human activity is mediated by cultural signs: words and tools, which cause changes in that activity, and thus its internal mental reflection (Vygotsky 1978). Vygotsky's work was continued by others including Leontjev who developed a conceptual framework for the theory of Activity. (Leontjev 1981). The theory therefore has a well-established tradition and has been applied in education, linguistics, anthropology, cultural research and more recently $\mathrm{HCl}$ (Kaptelinin 1994), computer science, (Bodker 1991) and IS (Kuutti 1990). An excellent compilation of work on Activity Theory and computer-based systems can be found in the book by Nardi (1996).

According to Kuutti (1996), Activity Theory is "a philosophy and cross-disciplinary framework for studying different forms of human practices and development processes, with both individual and social levels interlinked". It requires a paradigm shift for most western researchers and it is not easily comprehended on a first encounter. The following is an overview of key principles that could be applied to MSS. 


\section{A Comprehensive Unit of Analysis}

In Activity Theory the basic unit of analysis of all human endeavour is "activity", a broader more embracing concept than individual goal-oriented actions. The word "activity" has been chosen in English to be the best, but not perfect, equivalent of the Russian word "deyatelnost" roughly meaning human "doing" (performing or operating both physically and mentally). An activity is the minimum meaningful context for individual human actions and unless the whole activity is the unit of analysis, the analysis is incomplete. This is not unlike the General Systems Theory model which assumes that life in society is organised around complex systems which, when studied, should be treated as whole entities (Hasan 1998).

An MSS project usually requires an organisation-wide data model, cross-functional integration and cooperation from many sources and is often related to Data-Warehousing (Hasan 1995). The "activity" of MSS development must be studied as a whole and failure to take this broad view of the project can often be its downfall. Political rivalry and conflicts over "data ownership" must be anticipated and an MSS project team should realise that a system which informs management decisions can impact on the progress of the whole organisation.

\section{The Use of Tools}

Central to Activity Theory is the concept that all human activity involves the use of tools and that this distinguishes human activity from the activities of animals. Activity Theory recognises that there are physical, material tools, such as computer and psychological tools, such as language and ideas. While physical tools produce changes in the material object, psychological tools influence the psyche and behaviour of subjects. Modern computer systems act as both material and psychological tools to support human activity but this tool concept is not al ways recognised in $\mathrm{HCI}$ or IS.

Most of the initial work in HCI, such as that by Card et al (1983), was based on the cognitive science model of humans as information processors with sensory inputs and motor outputs not unlike the computer (Aboulafia \& Gould 1995). The interaction between human and machine was comparable to the interface between two computers where the output of one was the input to the other. This perceived equality of person and computer is evidenced by the term artificial intelligence. Some eminent $\mathrm{HCI}$ researchers have challenged that image. Norman (1991) uses the term "cognitive artefact" to describe a computer system and suggests that the real "interface" of interest is that between the artefact and the task. Carroll (1991) Jjkewise proposes a dynamic taskartefact cycle that serves the needs of the human user.

In the field of IS, task analysis of work process is more likely to look for those tasks which can be automated, than those that can be done by people with the computer as a support tool. An effective methodology for developing the latter type of systems is missing from most IS training curricula. One approach that has merit is that suggested by Ciborra and Francesco (1989), where a minimal set of hardware and software is put in place and further development is done as needed, either by end-users themselves, or by a professional team.

Activity Theory opens up the concept that, together with the physical MSS, the information and knowledge it provides should also be viewed as tools. This is related to the concept of internalisation that is discussed below and very relevant to the way a manager might use an MSS.

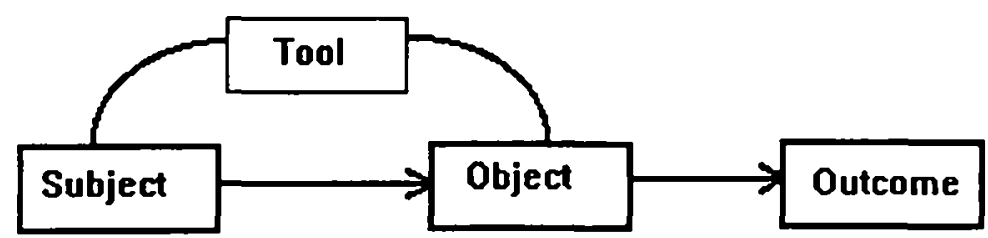

Figure 1. The Structure of an Activity

\section{The Structure of Activity}

An activity is undertaken by a human actor motivated towards an object and mediated by a tool as shown in Figure 1. Activities are distinguished from each other according to their objects. The word object is used in the sense of the "object of the exercise" and is related to the motive driving the activity, hence the term object- 
oriented activity is often used. In other words, transforming the object into an outcome motivates the existence of an activity (Kuutti 1996).

In the context of MSS use, it is proposed that the principal "activity" has the components shown in Figure 2 where the manager uses the MSS to make sense or understand the organisation and its environment in order to make more appropriate decisions.

\section{The Object-Orientedness of Activity.}

Activity Theory recognises that there are two kinds of objects: real, physical (material) objects and ideal (mental) objects, present in the subject's mind. The motive of an activity is always objective whether real or ideal and Activity Theory considers social and cultural properties of the environment to be as objective as the physical and biological ones. The object "sense-making" in Figure 2 is an example of a valid ideal object.

There is no activity without an object, that is activity is always purposeful although sometimes even the subject is not fully aware of that purpose. Activities can be polymotivated, an issue that must be addressed in MSS use, where the motivation may include the desire to be better informed and make better decisions but may also for status, to impress one's competitors or a variety of other reasons.

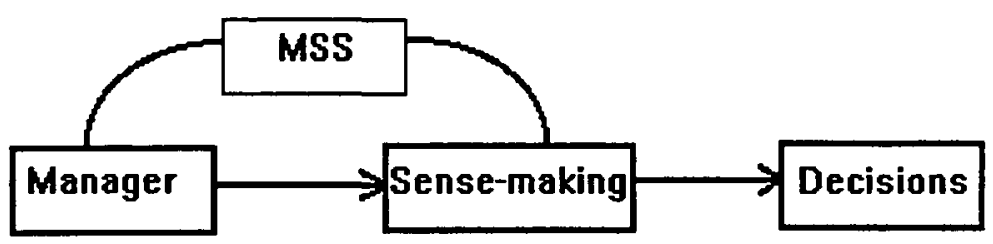

Figure 2. The Activity of MSS Use

\section{The Active Nature of Subject}

Another dynamic addressed by Activity Theory is the active nature of the subject of an activity. A person brings with them a whole range of biases that will affect how they approach the activity: previous experience, cognitive skills, personality and culturally determined traits. These will continue to evolve as the person undertakes the activity. In the activity of management decision making the subjects are the MSS users, usually high powered company executives.

The principal tenet of HCI has been "early and constant focus on the user" (Preece 1994) and user involvement in product design has been a constant theme. Communication between the triad of management, IS staff and system users, has often been difficult (Hasan \& Cheung 1994) and the HCI techniques of PD and JAD have proved to be effective in facilitating this communication. The users of a MSS can be a heterogeneous mix with different management styles, personalities and cognitive skills. A review of the research literature in this area could produce a checklist of possible combinations of characteristics with guidelines as to the possible systems design that may be suitable for each. The term "executive profiling" is becoming popular in the organisational management community.

\section{The Hierarchical Structure of Activities}

Participating in an activity involves performing conscious actions, that have an immediate and definite goal, and operations according to the hierarchy in Figure 3.

Activities are always related to motives, whereas actions are always related to goals. Goals are always conscious, but the operations which make up actions are usually non-conscious and automatically performed. Most importantly, although an activity can consist of many actions and operations in context, it is more than the sum of these. 


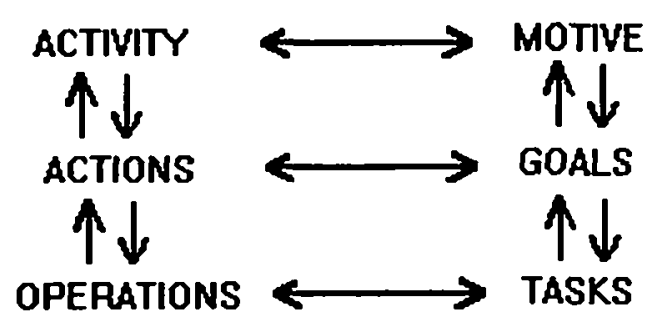

Figure 3 The Hierarchical Structure of Activity

The hierarchical structure shown in Figure 3 is a dynamic one. One activity usually is performed by several actions and operations. The same activity can be performed by different sets of actions. The same action can be used in different activities, as most subjects are often engaged in several concurrent activities.

This Activity Theory hierarchy has two significant messages for IS and HCI. One is that focussing on the whole activity, and not the detailed actions, may facilitate dialogue between the different stakeholders. At this top level, the purpose of the system is at issue, and cross-disciplinary communication should be easier.

Secondly the interplay between the levels of actions and operations is important with the desire for more usable, transparent computer systems. The aim in interface design is to allow the user to concentrate on conscious actions that are a significant part of the activity and relegate the use of the machine to the realm of unconscious operations.

\section{Context}

Activity Theory provides a model of humans in their social and organisational context. One of the main criticisms of the current cognitive science bias of $\mathrm{HCI}$ research is that it does not provide an appropriate conceptual basis for computer use in its wider social and organisational context. Activity Theory demands that activities are always studied in situ, taking into account the political, economical, social and cultural realities. Two examples of contextual concepts are Collective Activity and Tool Mediation.

\section{Collective Activity}

The basic activity structure applies to an individual subject. However as Kaptelinin (1996) observes the cultural-historical tradition emphasises the social nature of human beings and it would be natural to expect that Activity Theory would support the study of group activities.

The scheme of Engestrom (Kuutti 1996) as shown in Figure 4 extends the basic structure of Activity Theory to include group activities. In this scheme the entity of community is added to those of subject and object in the structure of activity. Whereas the subject-object relationship is mediated by the tool, the community-subject relationship is mediated by rules. The relationship between community and object is labelled "division of labour" but this term may need rethinking outside the Scandinavian tradition.

It is this model of activity that offers most promise for the study of MSS which are used in organisational contexts and may include communication facilities and tools for data manipulation to support decision making processes.

\section{Tool Mediation}

The structure of activity is strongly cognisant of the power of the tool to mediate and change the activity it supports. The mediating property of the tool modifies existing activities and opens the possibilities for new ones. Developers rarely consider how the tool they design will mediate activities, changing work practices as well as social and cultural norms.

It is common that, only as users become familiar with the system, can they appreciate the possibilities it offers. This is why an evolutionary prototyping method of development is recommended so that the system can grow with the user. This however means an ongoing commitment of resources as the system may not be signed off as complete even after a long period of real use. 


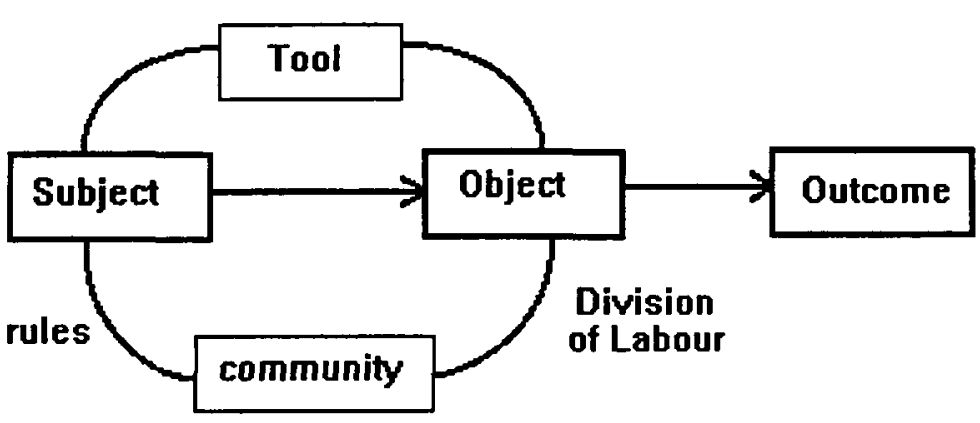

Figure 4 The Contextual Model of Activity

\section{Internalisation and Externalisation}

A fundamental principle of AT is the unity of consciousness and activity, where consciousness is considered to be the human mind as a whole and activity is considered as the interaction of the human with objective reality. This leads to the object oriented model of a subject's interaction with the environment.

The concept of internalisation is described by Vygotsky (1978) as the underlying mechanism for the origin of mental processes. Mental processes are derived from external actions through the course of internalisation. This is in apposition to conventional cognitive psychology which emphasises the mind as the source of action. It is through activity that we learn and internalise concepts that then become a psychological tool that is manipulation in the Internal Plane of Action (IPA). The IPA is a concept developed within Activity Theory that refers to the human ability to perform manipulation with an internal representation of external objects before starting actions with these objects in reality (Kaptelinin 1996). IPA is more general than the cognitive concepts of working memory and mental models and is well suited to the analysis of the processes of dealing with the "messy", unstructured problems of senior managers. The information provided and the knowledge managed by an MSS should support the user's IPA.

\section{THE STUDY: BACKGROUND AND METHOD}

The benefits of applying Activity Theory to MSS from both an IS and HCI perspective, is demonstrated in the following longitudinal case study which analysed the attempts made in a project to provide relevant and useful information to support quality management initiatives in an Australian university. Following considerable restructuring of the tertiary education sector in the 1980s, in the early 1990s the Australian government turned its attention to making the system work effectively and efficiently and it was felt that quality assurance could best be achieved through the use of performance indicators. This would require each university to vastly improve those information systems which provided teaching and research performance data.

The university project began in 1993 as a quality assurance initiative and evolved into a data-warehouse development (1994-1997). Though useful outcomes were produced, the project did not succeed in producing a useable MSS. The case study presented in this paper investigated both system development (IS) and usability (HCI) issues of the MSS project. The Activity Theory approach gave new insight into the processes and outcomes.

The author conducted the case study by observation and periodic interviews with principal stakeholders, over the five year period of the project. Data was collected in the form of transcripts of interviews, notes from observation and documents. The documents covered initiatives for quality assurance and performance indicators, planning and review, information systems policy and implementation as well as government and industry reports. As presented earlier in this paper, Activity Theory was considered the most appropriate method of qualitative data analysis suitable for this lengthy study, based on similar work by Boedker and Groebak (1996), Kuutti (1996) and Engestrom and Escalante (1996).

Whereas these previous applications of Activity Theory as a research tool were highly descriptive in nature, a much more categorical approach to data analysis was used in this study using the following steps:

1. The activities of interest were chosen and identified by defining their objects (in the Activity Theory sense).

2. Activity Theory diagrams were then drawn to display this data.

3. The structure of activity was used to filter and organise the data into categories of subject, outcome, community and tool.

4. The resulting structure was analysed as one or more activities 
5. Other activity theory concepts, such as the action/operation hierarchy, tool mediation and internalisation/externalisation, could then be used in a focussed way to interpret the data and draw conclusions.

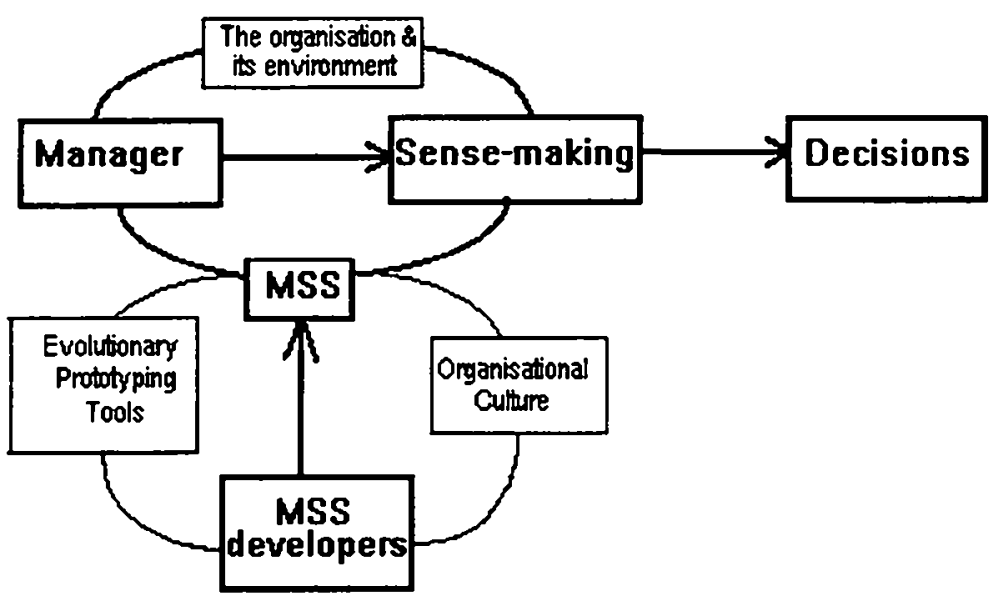

Figure 5. The relationship between the Activities of MSS use and development

\section{THE STUDY: ANALYSIS AND RESULTS}

The 5 steps listed above will now be demonstrated in a detailed analysis of the university MSS project. Words used with their specific Activity Theory meaning will be written in italics.

Step1. The first step here is critical and, using an approach similar to that of Boedker and Groebak (1996), it was recognised that the activities central to this study were firstly the activity of creating the MSS, for which the MSS is the outcome, and secondly the activity of being informed, which uses the MSS as a tool. These activities correspond respectively to an IS and an HCI perspective.

Step 2. These 2 activities are interrelated, as shown in Figure 5, using Engestrom diagrams for both activities. The top activity (Figure 4 inverted) is the use (HCl) activity and the lower one is the development (IS) activity, the object of which is the tool for the first activity. The terms use and development will be used for these two activities in the remainder of the paper.

Step 3 The quality assurance initiative and data warehousing development are now described using Activity Theory language and structure.

The first stage of the project included in this study was begun in early 1993 when a group, coordinated by the head of the Education Policy Research Program, was awarded a grant for the investigation of institution-based Quality Assurance, in line with government policy. The project group included representation from top university management, and had expertise in TQM as well as education and research performance evaluation. These were all potential subjects of the use activity. There was no permanent member of the group with IS development expertise and only occasional representation from the university's Administration Information Systems (AIS) department, who maintained the student database and other operational systems. Several group members, mainly those who had experience in the design of educational software, took on the role of subjects of the development activity. Their knowledge of IS development, in particular data analysis and design, was very limited.

The outcomes of this phase of the project were: (1) a set of research papers, (2) an Information Needs Audit for the broad spectrum of university staff and (3) a "user-friendly information system prototype to be accessible on line by staff of all ranks, in academic as well as administrative units, to support informed decision-making" (Fasano 1994). Unfortunately this prototype lacked credibility, as the technology, and IS development expertise, used for the prototype was restricted to the authoring systems that were used in the Education Department for computer-aided learning applications. The Information Needs Audit was a lengthy list of information requirements gathered from representatives of various groups on campus but fell short of identifying a workable set of performance indicators. There was no evidence that this list was comprehensive and there was no allowance for the way in which the needs would change over time. However it was a useful document. 
In 1994 there was a decision, driven by AIS, to create a Data-Warehouse in an effort to meet the rapid growing need for easily accessible information on students as identified in the Information Needs Audit. This Data Warehouse has been successfully implemented by AIS staff using an ORACLE database. The main reason for this choice was to be compatible with the anticipated release of a new student enrolment system by a consortium of Australian Universities. However development of this system is still a long way behind schedule and the Data-Warehouse continues to be used with regular daily updates from the legacy operational student database.

This development activity, performed by subjects with IS skills, has produced an outcome that is technically sound but not very useable. Control of end-user access to the Data Warehouse was not left with AIS but given to the Planning and Marketing Department (PMD) on the assumption that they would know what the users want. Employing contract programmers PMD have made three attempts to create a user-interface to the Data Warehouse: once using downloads into Excel spreadsheets, once using a web browser interface and a third enduser system using a suite of Oracle queries and reports. None of these systems have passed the prototype stage and PMD continue to use ORACLE programmers to generate ad hoc reports from the Data Warehouse, in response to specific requests from management, and for the periodic government reporting. The use activity in this case has virtually failed.

The most useful outcome of the whole project has been the realisation of the complexity of the information needs of university management at all levels. The quality assurance project's conclusion highlighted the need by all decision-makers in the university to access information "well beyond what is provided by pre-established lists of indicators" and that there is a "need of staff to access information processing capabilities, as well as just information, allowing individual and specialised reporting" (Fasano 1994).

Step 4. The language of Activity Theory is useful when describing this situation. It is clear that the objects of the two activities, development and use, are quite distinct. The object of one is to produce an artefact, the MSS, while the object of the other is to get a sense of how the organisation is preforming using that artefact. It is well known that the subjects of these two activities are often worlds apart and do not communicate well. The MSS developers are familiar with technical tools whereas managers often have little in the way of computing skills. It was apparent in the two projects of the study, that the activities are often confused, with project teams contain both sets of subjects, and one or other group tends to dominate.

At the Quality Assurance stage of the project, the activity of MSS use was dominant and the outcome was a somewhat useful "Information Needs Audit" but a weak system. The Data Warehouse development phase had a successful outcome in the Data Warehouse but still no useable interface that could provide an MSS for managers.

Using Figure 5 as a model it is clear that subjects of the MSS development activity and the subjects of the MSS use activity have a different perception of the aim of an MSS project. The developers aim to produce a robust, working system, while the managers want an easy-to-use tool that will provide a clear picture of the organisation's performance. Senior managers usually find it difficult to specify what sort of tool would be useful for their activity in a language that is meaningful a technical person. Both sets of subjects however are members of the same community which strongly depends on the outcomes of both activities.

Identifying the activities and their components is only the first phase in an Activity Theory analysis. All the other concepts of the theory, as described in Section 3 above can be brought to the analysis of the problem. Three of these are now briefly discussed.

\section{The Hierarchical Nature of Activities.}

This study is typical of most MSS projects run by teams composed of members, from different backgrounds, to whom different aspects of the project are important. The hierarchical structure of Activity Theory provides a means of dealing with this problem by insisting that the "unit of analysis" or "focus of study" should be a single identified purpose or object of the whole activity. An MSS project comprises development and use activities whose objects should be made clear to all. Once the main purpose is established and agreed by the team, then all points of disagreement should be on lower implementation issues at the action or operation level (see Figure 3 ). Activity Theory stipulates that an activity may be undertaken by different sets of actions and operations which may vary depending on the state of the subject, the tool and the community at the time. Less importance can then be placed on deciding which is the best set of actions to achieve the object of the activity. Team members, aware that there is no necessity to agree on one correct set of actions to carry out the activity, should find it easier to communicate and cooperate. 
The Dynamics of Activities.

The concept of tool mediation anticipates that changes will take place in an activity through the use of the tool. Participants in an MSS project usually focus on what sort of system would be useful for an activity as it is now. Activity Theory states that the question should be: "what sort of system would adapt with the users as they became more competent and reliant on the tool".

\section{The Internalisation of Information}

The process by which managers use information in the decision-making process is not well understood. The Activity Theory concept of IPA, introduced in Section 3.6 of this paper, deals with the way in which information is internalised by subjects as a mapping from the external world. This concept could be used to guide the design of information structure and presentation in an MSS. Further research in this area is strongly recommended.

\section{CONCLUSION}

MSS are organisational systems that are normally the province of IS. However as systems which "informate" rather than automate, they differ from traditional organisational systems, in that they have uncertain specifications and a non- homogeneous user population. The field of $\mathrm{HCI}$ specialises in problems of users and the field of IS could, in general, benefit from some of its teachings. However both IS and HCI lack a sufficiently contextual and flexible methodology to adequately support the development and use of information systems to support senior managers.

The principles of Activity Theory have much offer both IS and $\mathrm{HCI}$ and could be an appropriate philosophical and theoretical foundation for the study of systems such as MSS in the following ways:

- The holistic nature of activity provides an understandable focal point for cross-disciplinary discussion without considering the lower level detail where language and emphasis may differ.

- The model of activity, comprising subject, tool, object and community provides a useful framework for identifying stakeholders in an MSS, the activities in which they are engaged and the relationships between them.

- The Activity Theory hierarchy enables subjects to consider alternative sets of actions and operation to carry out the activity in a way which suits the specific goals and conditions of the situation.

- The principle of tool mediation is much more useful to the study of MSS than the traditional IS concept of the computer as a machine which automates work processes.

- The principle of internalisation is an apt description of the way managers use a support tool in the decision making process.

Nardi (1997), an anthropologist, believes that Activity Theory provides a common vocabulary to facilitate crossdisciplinary discussion and Activity Theory has already proved to be applicable for descriptive and explanatory studies of $\mathrm{HCI}$ and IS problems (for example the studies of Bodker 1991 and Engestrom \& Escalante 1996). Attempts are now being directed at a more prescriptive application of Activity Theory to problems of $\mathrm{HCI}$ using a design checklist (Nardi \& Kaptelinin 1997). The study presented in this paper suggested that another prescriptive use of Activity Theory could be to follow the 5 steps described here and to use the diagram shown in Figure 5 which relates system development to system use. This diagram, together with the dynamic and contextual principles of Activity Theory, could be a vehicle for describing the situation, identifying important issues and warning of common pitfalls.

\section{REFERENCES}

Aboulafia, A, Gould, E., (1995) Information Processing Vs Human Cognition: A Critical Review of Cognitive Approaches in $\mathrm{IT}$ and $\mathrm{HCl}$, International Society for the Systems Sciences 39th Annual Meeting, Amsterdam, , 293-304.

Alter S. (1996) Information Systems: A Management Perspective, 2nd edition, Benjamin/Cummings.

Blackler F. (1993) Knowledge and the Theory of Organisations: Organisations as Activity Systems and the Reframing of Management. Journal of Management Studies 30/6 863-884.

Boedker, S., (1991) Through the Interface - A Human Activity Approach to User Interface Design, Lawrence Erlbaum.

Boedker S. and Groenbak K. (1996) Users and Designers in Mutual Activity: An analysis of cooperative activity in systems design, in Y.Engestrom and D.Middleton (eds) Cognition and Communication at Work Cambridge University Press. 
Card S, Moran T. and Newell (1983) The Psychology of Human-Computer Interaction. Lawrence Erlbaum, Hillsdale.

Carroll JM. 1991 Introduction: The Kittle House Manifesto in J.M Carroll ed. Designing Interaction: Psychology at the Human-Computer Interface. Cambridge, 1-16.

Ciborra C. and Francesco L. (1989) Designing networks in Action: Formative Contexts and Post-Modern Systems Development Proceeding of SOST'89 IFIP TC9 Conference, Terrigal.

Davies L and Ledington P (1991) Information in Action: Soft System's Methodology Macmillan.

Engestrom Y. and Escalante V (1996) Mundane Tool or Object of Affection? The Rise and Fall of the Postal Buddy, in B. Nardi Ed Context and Consciousness: Activity Theory and Human Computer Interaction. MIT Press 325-374.

Fasano C (1994) Planning and Management Information Systems for Quality Enhancement and Assurance and Effective Resource Utilisation in the Higher Education System. DEET

Fidler C and Rogerson S (1996) Strategic Management Support Systems, Pitman, London.

Fiol C. (1992) Maps for mangers: Where do we go from here? Journal of Management Studies 29/3 267285.

Hasan H. (1995) Organisational Issues and Implications of EIS, Proceedings of ACIS95 Perth 207-218.

Hasan H. (1998) Activity Theory: a Basis for the Contextual Study of Information Systems in Organisations. In H. Hasan, E. Gould \& P. Hyland eds Information Systems and Activity Theory: Tools in Context, University of Wollongong Press.

Hasan H. \& Cheung L. (1993) Executives, Users \& IS in the 1990's Proceedings of the 4th ACIS Conference. Brisbane

Hasan, H. and Gould, E (1996) A Framework For EIS Development in The Public Sector to appear in the Proceedings of IRMA, Washington.

Hasan H, Jones C and E Gould (1996) Prototyping Tools for Expert and Novice Application Development Proccedings of the Empirical Studies of Programmers Conference, Washington

Hasan, H. and Lampitsi, S. (1995) Executive Access to Information in Australian Public Organisations, Journal of Strategic Information Systems 4/2.213-223

ISWORLD 1997 International electronic discussion group on IS

Kaptelinin, V. (1994) Activity Theory: Implications for Human Computer Interaction. In: Brouwer-Janse, M.D., Harrington, T. (eds.) Human-Machine Communication for Educational Systems Design, NATO ASI Series. Series F: Computer and Systems Sciences, v.129, Berlin : Springer-Verlag, 5-16.

Kaptelinin V (1996) Activity Theory: Implications for Human-Computer Interaction in B. Nardi Ed Context and Consciousness: Activity Theory and Human Computer Interaction. MIT Press 103-116.

Kuutti, K. (1990) Activity Theory And Its Application to Information Systems Research and Development, In: ISRA-90 Proceedings - Vol. I, IFIP TC 8 WG 8.2. Working Conference on the Information Systems Research Arena of the 90 's, Copenhagen.

Kuutti K (1996) Activity Theory as a Potential Framework for Human-Computer Interaction in B. Nardi Ed Context and Consciousness: Activity Theory and Human Computer Interaction. MIT Press, 17-44.

Kuutti K and Virkkunen J (1995) Organisational Memory and learning Network organisations: the Case of Finnish Labour Protection Inspectors Proceedings of the $28^{\text {th }}$ Annual Hawaii international Conference on Systems Science 313-322.

Leontjev, A.N. Problems of the Development of Mind Moscow: Progress 1981

Mantovani G, (1996) Social Context in HCI: A new Framework for Mental Models, Cooperation and Communication Cognitive Science 20 237-269.

Mintzberg H (1975) The Manager's Job: Folklore and Fact, Harvard Business Review, July-August 1995, 49-61.

Mintzberg H Raisinghani D and Theoret A. (1976) The Structure of "Unstructured" Decision Processes, Administrative Science Quarterly 21, 246-275.

Nardi B (1996) (editor) Context and Consciousness: Activity Theory and Human Computer Interaction. MIT Press

Nardi B (1996) Studying Context: A Comparison of Activity Theory, Situated Action Models and Distributed Cognition in B. Nardi Ed Context and Consciousness: Activity Theory and Human Computer Interaction. MTT Press 69-102.

Nardi B (1998) Where to from here? in Hasan, Gould \& Hyland (eds) Information Systems and Activity Theory; Tools in Context, University of Wollongong Press

Nardi B and Kaptelinin V (1997) Activity Theory: Basic Concepts and Application, Tutorial at CHI97, Atlanta. 
Neisser U. (1976) Cognition and Reality, Principles and Implications of Cognitive Psychology, W.H. Freeman.

Norman D (1991) Cognitive Artifacts in J.M Carroll ed. Designing Interaction: Psychology at the HumanComputer Interface. Cambridge, 17-38.

Preece J (1994) Human-Computer Interaction Addison-Wesley.

Randall R, O'Brien J, Rouncefield M and Hughes J. (1996) Organisational Memory and CSCW: Supporting the 'Mavis Phenomenon' Proceeding of OZCHI96, Hamilton NZ 26-33.

Rockart, J and DeLong, D.,(1988) Executive Support Systems, Dow Jones-Irwin.

Van Gigch J. (1978) Applied General Systems Theory Harper \& Row New York

Vygotsky, L.S. (1978) Mind and Society, Cambridge MA: Harvard University Press

Wagner C. (1995) Decision support for "messy" problems Information and Management 28 393-403.

Zuboff S (1988) In the Age of the Smart Machine Oxford 